\title{
Cruzamentos entre a música experimental e a música popular no trabalho de Chico Mello ${ }^{1}$
}

RESUMO: Junte o experimentalismo cageano com a canção popular. Este foi o caminho que o compositor Chico Mello trilhou em alguns trabalhos. O presente texto traça um percurso entre peças que evidenciam este cruzamento, tais como: John Cage na Praia número 0 e a série números 1 a 4 de mesmo nome, Amarelinha, Rayuela entre outras. Para além do cruzamento entre experimentalismo cageano e música popular este artigo aborda temas relevantes que emergem do trabalho de Mello, tais como: remix, apropriação, mimese, remediação, acaso, de(s)composição, ferramentas musicais, meta-partituras, intradutibilidade e diferenças culturais para citar as mais relevantes.

PALAVRAS-CHAVE: meta-remix, bossa-nova, música experimental

ABSTRACT: Mix the cagean experimentalism with Brazilians popular songs. This was a way the composer Chico Mello trailed in some of yours works. This paper traces a route between parts that show this crossing in his works, such as John Cage at the Beach Number Zero and the serie numbers 1 to 4 with the same name, as well as the pieces Amarelinha, Rayuela among others. Beyond from the cross between cagean experimentalism and pop music this article discusses relevant issues emerging from Mello's work, such as remix, appropriation, mimesis, remediation, chance operations, de-composition, musical tools, meta-scores, untranslatability and cultural differences to name the most important aspects.

KEYWORDS: meta-remix, musical tools, bossa nova, experimental music

\footnotetext{
*Giuliano Obici, artista-pesquisador com ênfase em arte sonora. Professor recém chegado no IACS-UFF, doutor pela ECA-USP, mestre em comunicação e semiótica pela PUC-SP e psicólogo pela UEM. Escreveu Condição da Escuta (7Letras). Recebeu o prêmio GigaHertz pelo Centro de Arte e Mídia (ZKM - Karlsruhe) e Experimental Studio (Freiburg). Forma o duo Ene menos um (n-1) com Alexandre Fenerich. Teve trabalhos apresentados no Imatronic Festival (Karlsruhe), Relevante Musik (Berlim), Next Generation (Karlshue), 319 Scholes (NY), Wien Modern (Viena), entre outros.
} 
Misture canções populares com elementos da música experimental proposta por John Cage. Foi esse encontro entre o experimentalismo cageano e a canção brasileira que Chico Mello sintetizou na peça John Cage na Praia número o (JCnP\#0) e que posteriormente com Silvia Ocougne criaram a série John Cage na Praia números 1, 2, 3 e 4 registradas no disco Música Brasileira De(s)composta (1996). ${ }^{2}$

Partindo do experimentalismo na música contemporânea tendo como material a música popular, JCnP parece desestabilizar balizas entre a chamada alta e baixa cultura, ou a dicotomia do erudito e popular. ${ }^{3}$ Nessas peças coexistem diferentes gramáticas, por um lado, os procedimentos e instruções cageanos contido no Song Books ${ }^{4}$ (1970) (musical-tools, simultaneidade, tabelas numéricas, acaso e silêncio) ${ }^{5}-e$, por outro, uma clara influência da bossa-nova (estilo de cantar e tocar violão de João Gilberto e Baden Pawell).

A proposta deste texto é abordar tais características partindo da peça John Cage na Praia número 0 (JCnP\#0 - 1990) ${ }^{6}$ passando por Amarelinha e mesmo a série de 1 a 4 de JCnP. A partir dessas peças pretendemos apresentar e discutir processos e conceitos que dialogam com o experimentalismo e a canção no trabalho de Chico Mello. A escolha de partir da peça JCnP\#O se deu por apontar um caminho singular no uso da canção partindo de amostras (sample) como material composicional, tocados sem uma linearidade fixa. A peça, ao estilo voz-violão, é modulada por cortes e procedimentos que faz lembrar um tipo de jukebox em mal funcionamento, prenha de bossas-novas e canções, tocadas de forma não convencional. Sugere-se um tipo de meta-remix acústico, que também aponta formas de de(s)compor a partir da mimetização das canções, sinalizando características e preocupações éticas-estéticas no trabalho de Mello que pretendemos abordar partindo de suas influências.

\section{Influências}

A peça John Cage na Praia n. 0 pode ser pensada como uma confluência de vias diversas na jornada de Chico Mello. Tais vias partem ao menos de dois pontos: estudos formais e a música popular. Para traça-los melhor vale a pena entender o percurso tomado por ele.

Chico Mello (Luiz Francisco Garcez de Oliveira Mello), nasceu em Curitiba, estudou composição no Brasil com José Penalva ${ }^{7}$ e Hans Joachim Koellreuter; na Alemanha teve aulas 


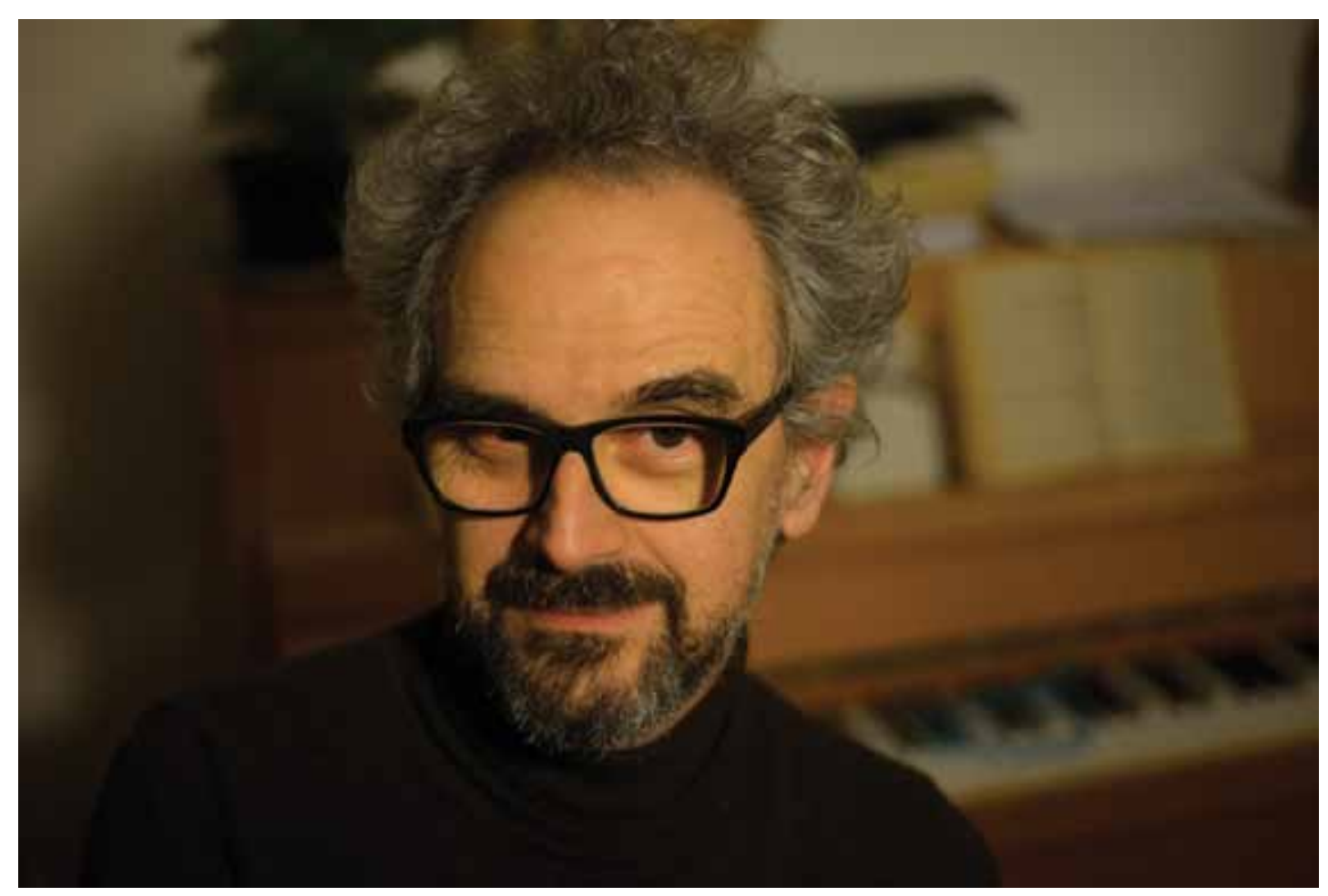

Chico Mello

com Dieter Schnebel e Witold Szalonek. Formou-se em violão pela Escola de Música e Belas Artes do Paraná, Medicina pela Universidade Federal do Paraná, Composição e Teoria Musical pela Universität der Künste Berlim e doutorado em musicologia pela Technische Universität Dortmund. Participou dos Festivais de Darmstadt (Alemanha) ${ }^{8}$ mas foi nos Cursos Latinoamericanos de Música Contemporânea ${ }^{9}$ (Uruguai, Brasil) onde encontrou um ambiente de discussão e posicionamento político sobre a identidade latino-americana. A partir dos Cursos se tornou possível traçar um caminho conciliatório entre música popular e contemporânea, onde o objetivo não estava em recriar folclorismo ou nacionalismo, mas olhar artisticamente sobre o corpo da musical latino-americano. 
Paralelo aos estudos formais de musica em Curitiba, Mello tomou gosto pela canção popular. A bossa nova teve forte impacto na sua formação, conhecendo-a através dos irmãos, dos discos e do programa Fino da Bossa ${ }^{10}$. Influenciado pelo estilo de João Gilberto e o violão de Baden Powell foi aprendendo as músicas de ouvido. "Aprendi tudo tirando na agulha, fazendo o disco rodar em dezesseis rotações para ouvir uma oitava abaixo e conseguir tirar os acordes, porque era muito rápido." (MELLO\&OBICI:2013) Vale lembrar que na época, final dos 1960 e início dos 70, a capital paranaense era uma cidade provinciana. O acesso a músicas era restrito, comparado ao Rio de Janeiro por exemplo. Nesse contexto, a escuta mediada pelo dispositivo de reprodução teve um papel importante. Foi a partir dos discos que Mello conseguiu escutar, imitar e incorporar o repertório. Acabou aprendendo a tocar um grande repertório de canções. ${ }^{11}$ Esta prática de escuta, repetição, imitação e transcrição à partitura Ihe serviu como "escola" e forma de acumular um vasto repertório bem como exercício para adaptação e arranjos posteriores.

Em 1987 muda-se para Berlim com intuito de estudar composição e passa a tocar bossa-nova na noite. Participa da montagem de Song Books ${ }^{12}$ de Cage o qual Schnebel estava realizando. ${ }^{13}$ Em algumas das peças do Song Books de Cage, os interpretes são convidados a inventar uma série de ações livres, onde cada performer define parâmetros de um processo aleatório (change operation - operação do acaso), usando números entre 1 e 64. ${ }^{14}$ Alguns anos mais tarde compõe e grava com Silvia Ocougne as peças John Cage na Praia números 1 a 4 . Nestas peças ambos tocavam simultaneamente a partitura de Cage cada qual com seu repertório. Mello fez isso também com outras pessoas, seguindo a mesma lógica. "Cada um decidindo o número de canções e as coisas que queriam fazer e executavam ao mesmo tempo. O resultado é próximo a uma peça cageana, ou mesmo, de uma parceria." ${ }^{15}$ (MELLO: 2013)

\section{Meta-score: entre intérprete-performance-compositor}

A apropriação ou parceria que se refere faz parte da concepção de Song Books e de outros trabalhos cageanos que lidam com eventos genéricos e forma aberta. Por exemplo, em Music Walk ${ }^{16}$, Fontana Mix ${ }^{17}$ e Song Books, as partituras são como ferramentas musicais (musical tools $)^{18}$, que consiste em instruções para gerar partituras, dizendo de outra forma, partitura para gerar partituras (meta-partituras). Nessas peças uma parte do trabalho do intérprete-performer 


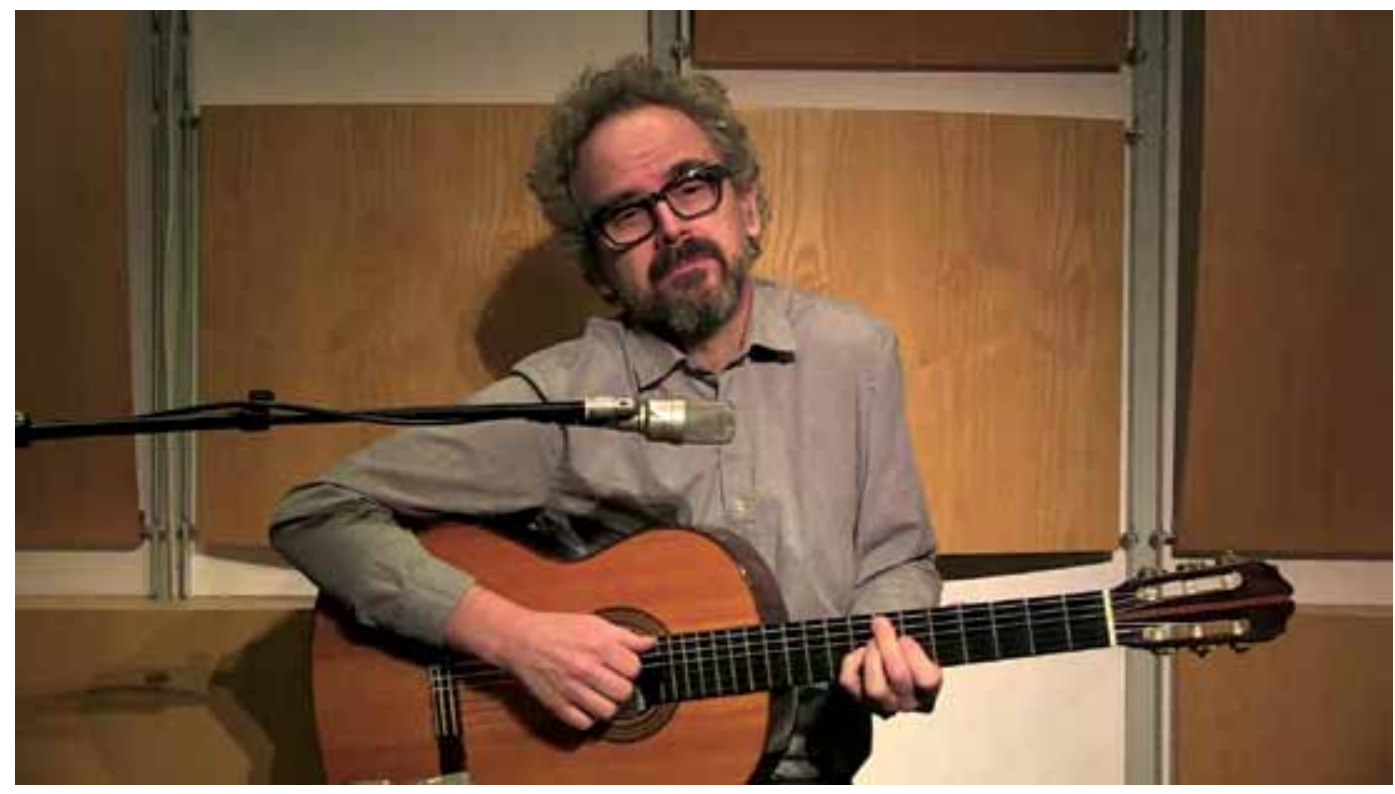

Chico Mello

é também confeccionar e montar sua própria partitura. Dentro dessa perspectiva as balizas estabelecidas entre autor e intérprete tendem a se borrar.

Um outro exemplo, que ilustra a zona difusa que se cria entre o lugar do compositor e do interprete em algumas peças de Cage, é a montagem de Variations // feita por David Tudor. ${ }^{19} \mathrm{~A}$ realização de Tudor de Variations /I, aproxima o trabalho do intérprete ao do compositor dado o caráter aberto da peça. ${ }^{20}$ Dizendo de outra forma, o trabalho de Cage e a interpretação de Tudor acaba por reposicionar os papéis intérprete-compositor, passando o compositor a ser um designer de sistemas composicionais. ${ }^{21}$

Ao comentar sobre JCnP\#O, Mello compara o uso que fez da partitura de Cage como uma inspiração gráfica. ${ }^{22}$ Isso evidencia que a partitura de Song Books carrega uma dupla função. A partitura é, ao mesmo tempo, fonte para gerar materiais e estruturar uma performance (musical tool), como também partitura que gera partituras e/ou ações genéricas (meta tool ou meta-score). ${ }^{23}$ 


\section{Desdobramentos}

Em 1992, quando estava trabalhando na peça para orquestra Amarelinha (1997), Chico Mello utilizou procedimentos parecidos, partindo do livro Rayuela (1963) de Julio Cortazar para estruturar e coordenar eventos da peça. ${ }^{24}$ Vale lembrar que o livro Rayuela, O Jogo da Amarelinha em português, é uma obra representativa do romance latino-americano experimental. O livro parte de uma ideia antiga, cultivada pelos dadaistas no início do século $\mathrm{XX}$, tendo o acaso como parte estruturante da peça, podendo ser lido de muitas maneiras.

Durante a composição de Amarelinha, Mello fará uso de bossas novas como forma de se territorializar frente ao universo estranho e desconfortável da orquestra. ${ }^{25}$ "Me sentia meio sozinho no meio daquela orquestra. Precisava de alguma companhia. Decidi então usar como material uma grande quantidade de bossas novas. Na mesma época tinham publicados os livros de bossa nova editados por Almir Chediak, chamado Songbook. "26 (MELLO\&OBICl:2013) A partir da compilação de Chediak, transcreveu as músicas para o computador sobrepondo-as, e ao executá-las simultaneamente escutou um bloco sonoro que the interessou explorar. A partir desse material acumulado de bossas-novas surgiram as peças orquestrais Do Lado de lá (1994) e Amarelinha (1997). Além de uma versão dessas peças para duas vozes e dois violões chamado Rayuela (2002).

Mello utilizou como ferramenta musical de Amarelinha, um roteiro específico proposto por Cotázar para realizar a leitura de Rayuela, ao modo de uma meta-partitura assim como Song Books fora para JCnP\#O. Além do roteiro de Cortázar outros elementos do livro - como número de páginas, capítulos, etc. - serviram para formular uma espécie de roteiro temporal, que Mello intercalou com suas próprias composições com bossas novas. Posteriormente, continuou desenvolvendo tais estratégias e materiais em outros trabalhos, como a já mencionada série de JCnP com a compositora Silvia Ocougne, bem como em trabalhos com a atriz e cantora Fernanda Farah.

Esses processos seguem o mesmo espírito dos métodos de composição de Cage, sem linearidade fixa, onde o acaso toma uma característica importante. Diferente de JCnP\#O, onde cada música tem seu próprio ritmo e estilo, em Amarelinha todas as músicas foram transpostas para a mesma tonalidade ou tom relativo, colocando-as também num mesmo pulso. No contexto da peças de JCnP\#O e Amarelinha Song Books de Cage e Rayuela de Cortazar 
representam meta-partituras por oferecem a estrutura e articulações dos materiais baseados em um repertório de canções, no sentido de uma de(s)composição performatizada coordenada; como um meta-remix que parte das músicas como um banco de dados de afetos e repertório acumulado.

É nesse sentido que o termo de(s)composição pode ser entendido, ao modo de um meta-remix, que mimetiza um tocador e anuncia procedimentos comuns aos meios digitais. JCnP\#O e a série $\mathrm{JCnP}$ parecem anunciar um modo de compor-escutar que se normatizou com as mídias digitais, através das listas e playlists, a cultura DJ e o remix, pela facilidade de copiar e colar ( $\mathrm{Ctrl}+\mathrm{C} \mathrm{Ctrl}+\mathrm{V})$, acumular e acessar um vasto banco de dados e/ou meta-dados de arquivos musicais. No entanto, vale ressaltar que trabalhos como JCnP surgem dentro de um regime anterior ao digital, mediado pelas mídias analógicas como o vinil, executada num regime acústico da voz-violão. Diferente do banco de dados digital o repertório acumulado de um cantor-violonista como Chico Mello carrega experiências que estão intimamente ligadas aos gestos e virtuosismo. Tais aspectos atualizam camadas múltiplas, muitas vezes impercetíveis e intraduzíveis no contexto digital. Pensando dessa forma, ao desconstruir os fluxos das canções de(s)compondo a música brasileira, acaba-se também abrindo outras possibilidades para pensar e compor com o acumulo afetivo das canções. Essa parece ser também uma das características das peças $\mathrm{JCnP}$.

\section{Mimese do fonógrafo - lâmina cageana}

Em JCnP\#O Chico Mello é compositor e intérprete, canta, toca violão e "tamborim-caixa de fósforo." Como se fosse uma jukebox quebrada, ou ainda, uma vitrola em "funcionamento não convencional." Simulando falhas de uma vitrola, toca: ora em loop, repetindo trechos como um disco riscado; ora silencia, como se passasse de uma faixa para outra; ora arranha as cordas produzindo ruído, como se a agulha girasse em falso no sulco do vinil revelando o silêncio-ruído de fundo. 27

Os cortes e mudanças de um sample a outro, lembram o gesto de uma agulha pulando na superfície do vinil. A performance pode ser pensada como uma "mimese" 28 do funcionamento de uma vitrola esquizofrênica. Estaria ela relacionada à experiência de aprender a tocar as bossas novas escutando pelo vinil? Se tal associação for pertinente, podemos dizer que o 
violão de Chico Mello em JCnP\#0 emula procedimentos comuns de uma vitrola, impregnado pela sua experiência de aprender bossa nova de ouvido, guiados pelo processo do acaso. ${ }^{29}$ Tais procedimentos adquirem uma dimensão performática. O contraste entre o músico virtuose e a mimese esquizo da vitrola, provocam o nonsense ao conteúdo tocado. O mesmo pode-se dizer dos cruzamentos textuais das canções, gerando frases absurdas e desconexas. ${ }^{30}$ As vezes surgem sintaxes textuais que lembram poemas dadaístas, efeitos da colagem gerada pela lâmina cageana.

\section{Remediação e cópia falsa}

Partindo da premissa de que o conteúdo de qualquer meio é sempre outro meio - o conteúdo da escrita a fala, a palavra escrita a imprensa, etc. ${ }^{31}$ - podemos pensar a performance de $\mathrm{JCnP \# 0}$ como um tipo de remediação (remodelar mídias em novas mídias). Remontando procedimentos de execução do vinil transpondo para o violão, ou seja, remediando a vitrola no violão, porém num sentido inverso ao das novas mídias. ${ }^{32}$

A jukebox remediada no violão de Chico Mello, opera um estado de instabilidade aos códigos. ${ }^{33}$ Imitando procedimentos e falhas de uma vitrola, transforma a repetição fixa dada pela execução da máquina, em uma repetição viva e mutante, que descodifica e transforma os códigos. ${ }^{34}$ Paradoxalmente, este gesto que poderia ser considerado cópia ou plágio restitui as variações de sentidos do mesmo material. Diferente da cópia fixa que o vinil representa, enquanto artefato que preserva o original, a mimese em JCnP\#0 enfatiza a variação do material. Repetindo o mesmo material, tal ação produz diferenças, que o revitalizam. A mimese da performance produz variações, as vezes redundâncias, cópias, falsificações, "música falsa"35

Há nessa mimese uma positivação, que se dá pela "falha" da cópia exata. Mello sintetiza essa ideia pela expressão "música falsa", termo que surgiu após conversa com o percussionista africano Tourba Kapamby sobre a (im)possibilidade de tocar a música de uma outra cultura. "A verdadeira música é a música falsa" ${ }^{\prime 6} \mathrm{~A}$ potência dessa mimese que repete sempre algo que não é exatamente igual, o eterno retorno da diferença, da singularidade. Dizendo de outra forma, na tentativa de copiar sempre se cria algo a mais. Surge, por assim dizer, um tipo de ruído que revela o falso, o qual é, ao mesmo tempo, portador da singularidade de quem copia. 


\section{Contra-fragmentação: simultaneidade, não linearidade, coexistência de tempos}

Tanto JCnP\#O como Rayuela utilizam várias canções, picotando e condensado-as no tempo, sem executar mais de um sample simultaneamente. ${ }^{38}$ Cada trecho é executado um após o outro seguindo uma sucessão temporal de cortes secos, intercalados por silêncios. ${ }^{39}$ Embora a simultaneidade de eventos foi apontada em Song Books ${ }^{40}$ ela não foi possível em JCnP\#O, como foi utilizado por Melo e Ocougne nas outras versões JCnP\#1-4. ${ }^{41}$ No entanto, podemos falar de outra forma de simultaneidade ou sobreposição. No caso de JCnP\#0 a simultaneidade-sobreposição não ocorre no nível do material, mas ela se dá a partir dos resquícios mnemônicos que as canções in-concluídas ecoam. ${ }^{42}$ Se por um lado, a peça segue uma estrutura de cortes e quebras sequenciais, por outro, há um efeito de acumulação e sobreposição das lembranças de cada canção. A canção iniciada que não conclui sua frase, que não encadeia o sentido sintático textual original, permanecendo como resquício, como uma câmera de eco que ressoa lembranças passadas, no ato presente da performance, gerando expectativa futura. "Em vez de contraponto, contrafragmentação. Também múltiplos tempos (passado, presente, futuro) num ocorrer linear - paradoxo. E o acaso: o de perceber as fulminantes ideias-linhas de fuga." 43

Nesse sentido, se estabelece um tempo em bloco, um aglomerado de sensações, impregnando no repertório sensível e mnemônico do ouvinte. Há um valor agregado, o qual passa existir e pertencer a experiência como uma espécie de gramática sensível de repertório auditivo coletivo. ${ }^{44}$ Isso nos faz pensar que o uso da canção popular, como material composicional, lida com um complexo de sentidos. Se nenhum material é neutro ou isento de semânticas e gramáticas, com o uso da canção a trama de sentidos, referências e significados se multiplicam. O trecho de uma música conhecida é contaminado por um complexo de camadas, amalgamadas pelas relações afetivas que cada ouvinte estabeleceu durante sua vida. Ela é, portanto, um bloco de sensações.

Talvez, por isso, o uso do sample beira o risco da repetição do mesmo, a recepção enfadonha, associada ao remix que não reinventa e pode falhar. Diferente disso, o meta-remix acústico que JCnP\#O parece evidenciar um jogo complexo de assamblage dos blocos de sensações que tende a multiplicar e cruzar diversas camadas de sentidos. 


\section{Do "entre" e a intradutibilidade}

Se pensarmos a maneira como Chico Mello utiliza a canção em JCnP\#0, podemos dizer que ela não se restringe ao material articulado pela meta-partitura. O compositor utiliza a canção tanto pela ligação afetiva - um fã do estilo bossa-nova e aquilo que ela evoca enquanto aspectos culturais e subjetivos - como pela singularidade dentro da sua linguagem musical. Dizendo de outra forma, a canção popular é, para Mello, um ponto de segurança e partida para estabelece um diálogo com a cultura musical europeia, ${ }^{45}$ um fio de Ariadne que o guiará pelo labirinto polifônico que o cerca, Ihe oferecendo companhia, um sentir-se em casa. ${ }^{46}$

Além da canção representar um lugar de segurança pessoal para Mello, ela é um ponto de partida para se pensar as singularidades culturais, ${ }^{47}$ bem como linha de fuga para escapar dos discursos que enrijecem e cerceiam estilos. Isso tem relação com o tema dos deslocamentos culturais (multikulturelles Missverständnis) que se espalham em outros trabalhos de Chico Mello. Um exemplo é a peça Todo o Canto (1996) - onde decide não compor sua própria música mas trabalhar com o repertório de uma cantora italiana especialista em canto indiano Dhrupad e uma cantora indiana expert em Bel Canto; onde as inversões e cruzamentos cultuais e de identidades são também elementos composicionais. Nessa mesma linha de trabalho, estão Foreing Steps (2012), Tropeço (2006), Hui Liu, où la varie musique (2003), La fausse musique (2000). Tais peças evidenciam misturas, assemblage musical e também assemblage de assemblage culturais deslocadas.

Tomando esses aspectos é possível dizer que Mello lida com um conjunto de fatores que apontam: paradoxos multiculturais, regionalismos, deslocamentos, intradutibilidades (Unübersetzbarkeiten), world music. Assim como JCnP\#0 esses trabalhos citados, tendem a tensionar a noção de falso e verdadeiro, original e cópia, sintetizado pela noção de "música falsa" 48 a qual, por sua vez dialoga com a "verdadeira mimese" em Derrida - como algo entre dois sujeitos que produzem e não entre duas coisas produzidas. ${ }^{49}$

Para concluir, vale esclarecer, que, se os termos neste texto foram apresentados de forma polarizada - alta $\mathrm{x}$ baixa cultura, erudito $\mathrm{x}$ popular, identidade $\mathrm{x}$ alteridade, mediação $\times$ remedição, original $x$ cópia, verdadeiro $x$ falso - assim o foram para enfatizar o campo de forças que esses polos estabelecem. A tensão desses polos evidencia um campo de distâncias, 


\author{
diferenças, contradições e paradoxos. O trabalho de Chico Mello parece habitar esse espaço \\ "entre" linguagens, estilos e culturas musicais, assumindo o difícil exercício de tornar audível \\ o intraduzível.
}

\title{
Notas
}

1 Este texto é uma revisão do artigo publicado na revista sueca Nutida Musik "John Cage p stranden: Chico Mello förvandlar skivsperlaren till en akustik gittar och spelar bossa nova över öppna partitur och den experimentalla romanen." Nutida Musik, v. 2, p. 28-35, 2013.

2 O disco Música Brasileira De(s)composta (1996) foi lançado pela Time Scaper Music Publishing GMBH.

3 No contexto da canção popular brasileira, a bossa-nova introduziu o padrão de uma música intelectualizada, marcada por influências literárias e eruditas, do gosto universitário ou estilizado. ... com harmonias vindas da música erudita (especialmente o impressionismo francês), letras enxutas e construtivistas, timbres pesquisados e influências da canção americana (Cole Porter) e do jazz. Trata-se de uma arte moderna na ironia e na consciência dos processos de construção (o 'Desafinado', o 'Samba de uma Nota Só') , que ressoou nas suas harmonias e na sua batida os sinais de um país capaz de produzir símbolos de validade internacional não-pitorescos: Brasília, o futebol campeão mundial, uma música inventiva e que se tornou depois quase um módulo industrial de som-aeroporto (além de influenciar até hoje a música americana e européia, do jazz ao rock)."(Wisnik, 2004, p.208)

4 Song Books (1970) tem três volumes: Solos for Voice 3-58, Solos for Voice 59-92 e o terceiro entitulado "Instructions" que contém várias tabelas e materiais necessário para a execução de algumas peças.

5 Tais elementos estão previstos em Song Books. "Any resultant silence in a program is not to be feared. Simply perform as you head decided to, before you knew what would happen." (Cage, 1970, p.1)

$6 \mathrm{JCnP \# O}$ é uma peça de Chico Mello que não foi registrada em disco. Após escutá-la no festival Ultima em Oslo no ano de 2012 convidei o compositor para gravar um video, o qual pode ser encontrado no link https://youtu.be/-8k2TRBRdmY acessado 20.07.2015.

7 Amigo da família de Chico Mello José Penalva "era o compositor mais experimental da cidade onde só haviam dois".(Mello\&Obici:2013),

8 Chico Mello trabalhou como arranjador, compositor e instrumentista em grupos de música popular e música experimental no Brasil. Desde 1987 residindo na Alemanha (Berlim), onde trabalha como compositor e performer. Lecionou teoria e violão na Escola de Música e Belas Artes do Paraná, violão na Musikschule Neuköln, Berlin, improvisação e composição na Universität der Künste, Berlin. Realiza projetos em diferentes áreas como teatro musical, música silenciosa, canções experimentais em colaboração com Silvia Ocougne, Dieter Schnebel, Daniel Ott, Arnold Dreyblatt, Amelia Cuni, Burkhard Schlotthauer, Carlos Careqa, Fernanda Farah, Nicholas Bussman e também com os conjuntos Maulwerker, Contemposonoro, Kammerensemble Neue Musik, Mosaic Ensemble, Remix Ensemble, Ensemble Aventures entre outros.

9 Os Cursos Latinoamericanos de Música Contemporânea tiveram 15 edições realizadas em diferene países da américa latina (Uruguai, Argentina, Brasil, República Dominicana e Venezuela) durante 1971 a 1989. (Cf. Soares 2006)

10 O programa Fino da Bossa ajudou a difundir e apontar outros rumos à música popular brasileira o qual era apresentado pelos intérpretes Elis Regina e Jair Rodrigues, produzido e dirigido por Manoel Carlos e Nilton Travesso, e esteve no ar pela TV Record entre 1965 e 1967 
11 "Tirei tudo de Baden de ouvido, já que não haviam partituras naquele época". (Mello 2013)

12 O Song Books é uma coleção de trabalhos composto e compilado pelo John Cage em 1970. Ele contém peças de quatro tipos: canções, canções com eletrônica, direções para performance teatral, e direções para performance teatral com eletrônica. "Any of these may be performed by one or more singers." (Cage, 1970, p.1)

13 "Na época o Schnebel realizou uma montagem do Song Books do Cage, da qual participei". (Mello\&Obici:2013)

14 Mello perguntou: "E se eu colocar o meu repertório de canções aqui, o que será que vai sair disso?" O Schnebel falou: Bacana. Experimenta. Surgiu então John Cage na Praia número 0, embora ainda não com o esse título." (Mello: 2013)

15 "Given two or more singers, each should make an independent program, not fitted or related in a predetermined way to anyone else's program." (Cage, 1970, p.1.)

16 “Music Walk has no existence as a score, but rather exists as a means of making scores - a compositional process handed over to the performers to execute." (Prichett, 1993, p.128)

17 Sobre Fontana Mix o musicólogo Volker Straebel escreve "The score provide a 'musical tool' to create a new piece or to alter or perform existing material created by Cage, an "is not limited to tape music but may be used freely for intrumental, vocal or theatrical purposes" (CAGE, Fontana Mix [1958]) Whit this, Cage not only accepted the performative aspect of eletronic music production in the studio, but radically extended his changed approach to the situation of the performance of music for fixed media." (Straebel, 2012, p. 109)

18 James Prichet escreve sobre Music Walk de John Cage e o caminho que parte da partitura para as ferramentas musicais. "In the pieces composed from 1958 to 1961, he ceased making musical scores in any sense of the term, and began making what I refer to as 'tools': works which do not describe events in either a deterinate or an ideterminate way, but which instead present a procedure by which to create any number of such descriptions or scores." (Prichett, 1993, p.126)

19 "The description of Tudor's realization and performance of Variations II raises the question of authorship: Is this really a performance of Cage's composition?" (Prichett, 2004, p. 15)

20 "I consider Tudor's realization of Variations II to be a composition in its own right." (Prichett, 2004, p. 16)

21 "Thus, while the performer's role has changed greatly in these news works, that of the compose has not: he still is primarily a designer of compositional systems." (Prichett, 1993, p.128).

22 "Eu simplesmente usei uma inspiração gráfica. É como fazer uma peça baseando-se em um quadro." (Mello: 2013)

23 "The basic unit of Variations II is the measurement of a point to a line. The interpretation of that measurement is completely open: it can represent anything at all, at any level, structural or particular. A point can represent any event or component of an event, and a line can represent any characteristic of such events. In his other tool compositions, Cage presented rules for the creation of a score and had the performer execute them. Here there are no rules: there is a single, simple model - the measurement of distances - to be used in making whatever rules the performer deems necessary. In this sense, Variations II is more than a tool, it is a meta-tool." (Pritchett, 1993, p.137)

240 livro Rayuela de Julio Cortázar, [1963] 1984 traduzido em português como O Jogo da Amarelinha.

25 Esse aspecto da canção por assumir a sensação de companhia e segurança é desenvolvida em Deleuze e Guattarri a partir do conceito de território. (Obici, 2008, p.77-78) 
26 "The basic philosophy was that each songwriter would accompany the entire production process, from the initial selection of the repertoire, through the proofreading of lyrics and music, photo research, and even on to the introductory texts." (Chediak, 1990, p.8)

27 Outros elementos aparecem que não estão relacionados à mimetização da vitrola diretamente, como a adaptação-gambiarra improvisada do uso da caixinha de fósforo mimetizando a função do pandeiro no contexto do samba-choro, algo próprio ao contexto das rodas de samba-canção e serestas brasileira.

28 Como aponta o termo em sua tese "Mimese e a construção musical" publicada em 2010. "Mello, Chico. Mimesis und musikalische Konstruktion. Aachen: Verlag Shaker, 2010.

29 Assim como a música pop e o rock, a bossa-nova foi amplamente difundida através das gravações, sendo a performance uma mimese da gravação."The primary experience of the music is as a recording; the the function of live performance, therefore, is to authenticate the sound on the recording. In rock culture, live performance is a secondary experience of the music but is nevertheless indispensable, since the primary experience cannot be validated without it." (Auslander, 2008, p. 185)

30 Aspectos semelhantes escreve Júlio Medaglia ao comentar sobre a influência da poesia concreta na bossa-nova em um texto de 1966 chamado Balanço da Bossa. Ao referir a bossa nova, escreve que ela "faz uso não raro, de efeitos e artifícios extraídos da literatura de vanguarda - particularmente da Poesia Concreta - fundindo palavras ou evidenciando e valorizando a sonoridade das sílabas como elemento musical." (Medaglia, in Campos, 1974, p.85)

31 Como escrever McLuhan: "the 'content' of any medium is always another medium. The content of writing is speech, just as the written word is the content of print, and print is the content of the telegraph" (McLuhan, 1964, p.23-24)

32 "Remediation can work in both directions: older media can also refashion newer ones. Newer media do not necessarily supersede older media because de process of reform and refashioning is mutual." (Bolter; Grusin,1999, p.59)

33 “Se é verdade que cada meio tem seu código, e que há incessantemente transcodificação entre os meios, parece que o território, ao contrário, se forma no nível de certa descodificação." (Deleuze, Guattari, [1980] 2005, v.4, p. 131).

34 “Derrida versteht dies als Grammatikalität. „Die Imitation wäre demnach zugleich das Leben und der Tod der Kunst."129 Die Möglichkeit der Wiederholung und Veränderung des Originären (Repräsentation), die Technik, verbirgt das der Kunst innewohnende Todesprinzip. In seiner Ablehnung des rationalen Formalismus (Materialismus und Sensualismus) versteht Rousseau die Harmonie als den Tod des Gesangs.130 Im Gegensatz zu dem guten Prinzip der Imitation - das Lebensprinzip - ist dieser Tod schon in einem anderen, schlechten Prinzip, in der Melodiegenese zu finden, es zeigt sich in der Berechnung der auf eine Tonart bezogenen Intervallverhältnisse, also in einem harmonischen Prinzip." (Mello, 2010, p. 67)

35 Um processo semelhante de apropriação ocorre por exemplo em Cheap Imitation (1969) de Cage totalmente estruturada na composição Socrate (1918) de Erick Satie. "I'm not the least bit interested in telling others what they have to do. I'm not a policeman! It bothers me even more that, in the Song Books as well in Cheap Imitation, I acted exactly like I say others shouldn't. (...) I willingly admit that between the Song Books and Cheap Imitation, I hardly fulfilled the role of the composer as I defined it elsewhere. (...) I would say that my problem is to place my ideas on the improvement of the conditions of life in this world in relation to my viewpoints about composition... My work has stopped being purely musical. I mix musical needs with social needs." (Cage, 1981 p. 179) Cage, J.For the birds: in conversation with Daniel Charles. M. Boyars, 1981

36 “In einem Gespraäch mit dem afrikanischen Perkussionisten Tourba Kapamby sagte er zu mir im Hinblick auf die (Un)Möglichkeit, die Musik anderer Kulturen nachzuahmen:: 'La vrai musique c'est la fausse musique' auf Deutsch: Die wahre Musik ist die falsche 
Musik. Das hat mich zu einer Reihe com Stücken inspiriert, die ich, nicht ohne Selbstironie, 'multikulturelles Missverständnis' nenne." (Mello, 2005, p.32)

\section{Deleuze [1968] 2006}

38 "Aquelas bossas novas, por exemplo, foram sendo desarticuladas ao nível do átomo, recombinadas em outras moléculas, emprenhadas de silêncio, resignificadas a cada vem que cruzavam de forma deliciosamente irresponsável as fronteiras entre a nota e o ruído, arbítrio e acaso, som e gesto, afeto e razão." (Taborda, 2011)

39 Na parte sobre Instruções Gerais (General Directions) do Song Books escreve John: " Any resultant silence in a program is not to be feared. Simple perform as you had decided, before knew what would happen." (Cage, 1970, p.1)

40 "Given two or more singers, each should make an independent program, not fitted or related in a predetermined way to anyone else's program." (Cage, 1970, p.1.)

41 Além do CD Música Brasileira De(s)composta há um registro da performance de Ocougne e Mello filmado por Konstanze Binder no "the Kitchen" em 1997 (Berlim Kreuzberg). https://youtu.be/hZin88KTAW4 acessado 20.07.2015

42 Como escreve Chico Mello no texto "Amarelinha - Ou: como chegamos à música, ao som, à vida, à língua?" "A questão da repetição, da memória, da homo/heterogeneidade ao costurar os fragmentos. Não escondo meu amor pela inebriante confusão que Feldman me causa, e pelo humor e desvio ou multiplicidade de cenas que Cage me suscita ("Credo in us", "Song books")." (Mello, 1996a)

43 Mello, 1996a

44 “Das Sample erhält äesthetische Relevanz durch den Kontext, in den es gestellt wir, $\mathrm{n}$ di Fragestellung, die mit ihm provoziert werden soll. Auf diese Weise eignet sich die Kunst Wirklichkeit an, ohne selbst ihren künstlischen Charackter zu verlieren." (Sanio, 2008, p.12)

45 “In der urbanen Popularmusik Lateinamerikas findet sich so von Anbeginn eine ausgeglichene Mischung, da die kulturellen Kräfte eher horizontal ausgehandelt wurden. Erst durch das wirtschaftliche Interesse der Musikindustrie ging diese Balance verloren. In der westlichen Kunstmusik ist eine allmähliche Befreiung von den traditionellen westlichen Konstruktionsprinzipien - Diskursivität, Kontrast (Konflikt), Kontrapunkt, thematische Arbeit - erst seit Satie und Debussy zu erkennen, und dies dank ihres Interesses an nicht- europäischer Musik. Später stellten Cage und Fluxus-Komponisten wie Nam June Paik und La Monte Young alle Paradigmen der Kunstmusik in Frage - und noch einmal war nicht-europäische Musik bzw. Philosophie und Religion ein wichtiger Ausgangspunkt. Es ist jedoch bemerkenswert, dass die zuletzt genannten radikalsten Dekonstruktionen europäischer Musik vom amerikanischen Kontinent ausgingen. Ungeachtet ihrer Anlehnung an den Orient, waren sie auch Antworten auf eine Identitätsfrage eines kulturell hybriden Kontinents." (Mello, 2010, p. 274)

\section{Cf. Obici, 2008.}

47 "Quando evocamos a canção ou as vocalizações em nós, não apenas criamos o território, o em-casa, que protege das forças caóticas, como também colocamos para funcionar algo fugidio, como uma melodia que leva para além dos limites de segurança. A linha melódica pode se tornar linha de fuga." (Obici, 2008, p.78)

48 Mello, 2005, p.32-33 
49 "Mimesis here is not the representation of one thing by another, the relation of resemblance or identification between two beings, the reproduction of a product of nature by a product of art. It is not the relation of two products of two productions. And of two free-

doms... 'True' mimesis is between two producing subjects and not between two produced things." (Derrida, 1998, p.272)

\section{Referências}

AUSLANDER, Philip. Liveness: Performance in a Mediatized Culture Routledge, 2008.

BEIMEL, Thomas. "Die 'falsche' Musik ist die wahre!: Ein Portät des brasilianischen Komponisten Chico Mello". Köln: Musik Texte: Zeitschrift für Neue Musik. v.113. 2007, (27-30).

BOLTER, Jay David \& GRUSIN, Richard. Remediation: Understanding New Media. Cambridge: MIT Press, 1999.

CAGE, John. For the birds: in conversation with Daniel Charles. Boston: Boston: M. Boyars, 1981.

Song Books I: Solos for Voices 3-58. C.F. Peters Corporation. New York: Henmar Press, 1970.

Song Books Instructions. C.F. Peters Corporation. New York: Henmar Press, 1970.

CAMPOS, Augusto de. Balanço da Bossa e outras bossas. 2a. edição. São Paulo: Perspectiva, 1974.

CHEDIAK, Almir. Tom Jobim Songbook. Vol.1. Rio de Janeiro: Lumiar, 1990.

CORTAÁZAR, Julio. Rayuela. Barcelona: Seix Barral, 1984.

DELEUZE, Gilles. Différence et répétition. Paris: Epiméthée P.U.F, 1968. Ed. Bras. Diferença e repetição. Ed. 2. Trad. Luiz Orlandi e Roberto Machado. Rio de Janeiro: Graal, 2006.

DELEUZE, Gilles GUATTARI, Félix. Mille Plateaux - Capitalisme et schizophrénie. 2. Paris: Minuit 1980. Ed. Bras. Mil platôs: capitalismo e esquizofrenia. Vol. 4. Rio de Janeiro: Editora 34, 2005.

DERRIDA, Jacques. The Derrida reader : writing performances. Lincoln: Lincoln: University of Nebraska Press, 1998.

SANIO, Sabine. 'Sample Acts'In Positionen.Vol. 77. Mühlenbeck: Verlag Positionen, 2008, (12-15)

MCLUHAN, Marshall. Understanding Media: The extension of man. Times Mirror. New York: New American Library, 1964

MELLO, Chico. ‘Unübesetzbarkeiten'In Positionen. Vol. 63. Mühlenbeck: Verlag Positionen,2005.(32-33)

. Mimesis und musikalische Konstruktion. Aachen: Verlag Shaker, 2010.

Amarelinha: como chegamos à música, ao som, à vida, à lingua? Musa Paradisíaca (coord.: Joseli Baptista e Francisco

Faria) Curitiba: Jornal Gazeta do Povo 1996. http://www.latinoamerica-musica.net/compositores/mello/amarelinha-po.html(acessado 20.03.2013)

OCOUGNE, S. Música Brasileira De(s)composta.TimeSacaper Music Publishing GMBH, 1996.

MELLO, Chico e BRANDÃO, Helinho. CD Água: Curitiba: SIR Laboratório de Som e Imagem, 1984; Berlim: Scape Studio, 2000. (remasterizado)

MELLO, CHICO e OBICl, Giuliano. Entrevista sobre John Cage na Praia Número 0. Berlim: datilo, 2013. 
OBICl, Giuliano. Condição da escuta: mídias e territórios sonoros. Rio de Janeiro: 7 Letras FAPESP, 2008.

John Cage p stranden: Chico Mello förvandlar skivsperlaren till en akustik gittar och spelar bossa nova över öppna partitur och den experimentalla romanen. V.2.Stockohlm: Nutida Musik, 2013. (28-35)

PRITCHETT, James. The music of John Cage. Cambridge University Press, 1993.

David Tudor as Composer/Performer in Cage's Variations II. Leonardo Music Journal, Vol.14, 2004, (11-16).

SOARES, Teresinha Rodrigues Prada. A utopia no horizonte da música nova. 2006, http://www.teses.usp.br/teses/disponiveis/8/8138/ tde-10072007-103613/pt-br.php. (acessado 30.03.2013)

STRAEBEL, Volker. Media-specific artists records between reproduction and performance. São Paulo: IV Seminário Ciência Música Tecnologia: Fronteiras e Rupturas - Trabalhos Convidados, 2012.

TABORDA, Tato. Chico Mello. In Encarte da coletânea de CD Chico Mello: 20 anos entre janelas (música experimental de 1987-2007): Curitiba: Lei de Incentivo a Cultura, 2011.

WISNIK, José Miguel. Sem receita: ensaios e canções. São Paulo: Publifolha, 2004. 